\title{
Randomized, double-blind, placebo-controlled superiority trial of the Yiqigubiao pill for the treatment of patients with chronic obstructive pulmonary disease at a stable stage
}

\author{
FENG-SEN LI ${ }^{1 *}$, YAN-LI ZHANG $^{1 *}$, ZHENG LI $^{2}$, DAN XU² ${ }^{2}$ CHUN-YAN LIAO ${ }^{2}$, \\ HUAN MA ${ }^{1}$, LI GONG ${ }^{3}$, JUN SU ${ }^{1}$, QI SUN ${ }^{4}$, QIAN XU ${ }^{2}$, ZHEN GAO $^{2}$, LING WANG ${ }^{1}$,

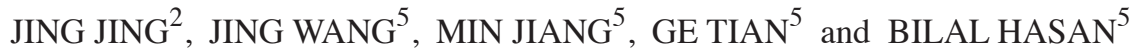 \\ ${ }^{1}$ Department of Integrated Pulmonology; ${ }^{2}$ National Clinical Research Base of Traditional Chinese Medicine, \\ ${ }^{3}$ Department of Geriatric Medicine; ${ }^{4}$ Medical Research Design and Data Analysis Center; \\ ${ }^{5}$ Xinjiang Laboratory of Respiratory Disease Research, Traditional Chinese Medicine Hospital \\ Affiliated with Xinjiang Medical University, Ürümqi, Xinjiang 830000, P.R. China
}

Received June 11, 2015; Accepted July 15, 2016

DOI: $10.3892 /$ etm.2016.3680

\begin{abstract}
In traditional Chinese medicine (TCM), the Yiqigubiao pill is commonly used to enhance physical fitness. The current clinical trial was designed to evaluate the efficacy and safety of the Yiqigubiao pill as an adjuvant therapy for patients with stable chronic obstructive pulmonary disease (COPD). The current trial was a randomized, double-blind, placebo-controlled superiority trial. The participants were recruited from outpatients at the Traditional Chinese Medicine Hospital affiliated with Xinjiang Medical University (Ürümqi, China) between February and September 2012. All participants were patients with stable COPD that were randomized
\end{abstract}

Correspondence to: Professor Feng-Sen Li, Department of Integrated Pulmonology, Traditional Chinese Medicine Hospital Affiliated with Xinjiang Medical University, 116 Huanghe Road, Ürümqi, Xinjiang 830000, P.R. China

E-mail: fengsen602@163.com

Dr Bilal Hasan, Xinjiang Laboratory of Respiratory Disease Research, Traditional Chinese Medicine Hospital Affiliated with Xinjiang Medical University, 116 Huanghe Road, Ürümqi, Xinjiang 830000, P.R. China

E-mail: bilal1204@hotmail.com

${ }^{*}$ Contributed equally

Abbreviations: YQGB, Yiqigubiao pill; $\mathrm{Pb}$, placebo; $\mathrm{COPD}$, chronic obstructive pulmonary disease; AECOPD, acute exacerbation of COPD; 6MWD, 6-min walking distance; CAT, COPD assessment test; FEV1, forced expiratory volume in $1 \mathrm{sec}$; FVC, forced vital capacity; MMRC, Modified Medical Research Council; CRF, case report form; BODE, body mass index, obstruction, dyspnea and exercise

Key words: Yiqigubiao pill, chronic obstructive pulmonary disease, randomized controlled trial, traditional Chinese medicine, stable stage to the Yiqigubiao pill (YQGB; $n=84)$ or placebo $(\mathrm{Pb} ; \mathrm{n}=87$ ) groups. The occurrences of acute exacerbation (AE) of COPD during the trial were recorded. Lung function value assessments, scoring of life quality and exercise endurance, arterial blood gas analysis and serum inflammatory cytokines level determination were performed prior to and throughout the study. A total of 139 participants completed the intervention and 132 participants completed the study. The interval between the initial intervention and the first AECOPD was greater in the YQGB group compared with the $\mathrm{Pb}$ group $(\mathrm{P}<0.01)$. The incidence rate of AECOPD was lower in the YQGB group than in the $\mathrm{Pb}$ group $(\mathrm{P}<0.01)$. Subsequent to the intervention or at the end of the study, the 6-min walking distance difference was longer in the YQGB group compared with the $\mathrm{Pb}$ group $(\mathrm{P}<0.01)$. The scores reflecting life quality decline became lower in the YQGB group $(\mathrm{P}<0.01)$. The serum levels of proinflammatory factors were downregulated to a greater extent in the YQGB group compared with the $\mathrm{Pb}$ group. Thus, the Yiqigubiao pill is an efficient and safe adjuvant therapy for the treatment of stable patients with COPD.

\section{Introduction}

Chronic obstructive pulmonary disease (COPD) is one of the leading causes of health problems globally, with increasing morbidity and mortality which results in high social costs and economic burden of the patients (1-3). The Global Initiative for Chronic Obstructive Lung Disease (GOLD; updated 2011) defines COPD as a common, preventable and curable disease characterized by persistent airflow limitation (4). The severity of COPD is impacted by airflow limitation progression, the chronic pulmonary inflammatory reactions to harmful airborne particles or gases, the occurrence of acute exacerbation (AE) COPD and complications. Recurrent acute exacerbations result in a decline in immunity, which then gradually leads to frequent and severe pulmonary infections $(5,6)$.

The 2011 version of the GOLD indicates that COPD therapy should be based on the severity of the disease as 
determined by considering the clinical symptoms, the airflow limitation and the risk of AE of the patients, and not exclusively dependent on the airflow limitation assessment, as was the case previously (4). Therefore, COPD therapy should focus on minimizing the risk factors, relieving the symptoms, and preventing AE recurrence (7). However, the current principal therapeutics applied to the treatment of COPD, including the inhalation or administration of hormones, the inhalation of $\beta 2$ receptor agonists or $\mathrm{M}$ receptor antagonists, and home oxygen therapy, are unable to attenuate the progressive lung function loss in patients with COPD, although some of them improved lung function and/or quality of life, particularly in severe COPD (8-11). In addition, a number of the aforementioned treatments induce side-effects, which may result in adverse drug reactions such as osteoporosis, risks of cardiovascular diseases or cognitive function impairment (12-14).

Thus, it is necessary to establish novel strategies to treat COPD by alleviating the symptoms, reducing AE recurrence and delaying disease progression without causing adverse events. Previous clinical studies have determined that traditional Chinese herbal medicines may be candidates that are efficient in relieving the symptoms of COPD, particularly in patients at the stable stage $(15,16)$. In traditional Chinese medicine (TCM), it is thought that the symptoms of the majority of cases of stable COPD are attributed to qi deficiency in the lungs and spleen, typically followed by phlegm symptoms upon the progression of the disease (17). The principles of COPD treatment include the enhancement of functions of the lung and spleen, improving immunity and thus reducing AECOPD occurrence (18). Yiqigubiao formula, a preparation of compounds including Chinese herbs, has been used to treat recurrent airway inflammation or allergic rhinitis $(19,20)$. The Yiqigubiao formula is a decoction derived from an ancient formula of Shen-Ling-Bai-Zhu San (21) in addition to Erchen Tang (22). The major herbs used in the Yiqigubiao formula, such as Dang Shen, Bai Zhu and Fu Ling, have the function of reducing lung-heat, and regulating immune or anti-inflammatory responses (Table I) (23-25).

In order to evaluate the efficacy and safety of the Yiqigubiao formula for the treatment of stable COPD as a supplementary remedy, the current authors conducted a randomized, double-blind, placebo-controlled superiority trial. In the present clinical trial, it was demonstrated that the Yiqigubiao pill enhanced the efficacy of conventional therapy during the treatment of stable COPD by relieving clinical symptoms, reducing acute exacerbation and mitigating inflammatory responses, without causing significant adverse events.

\section{Patients and methods}

Ethics statement. The present study was approved by the Ethics Committee of the Traditional Chinese Medicine Hospital affiliated with Xinjiang Medical University (approval number, 2012XE008). All participants were informed that: i) Participation in the study was voluntary; ii) the participants were free to withdraw the trial at any time; and iii) all responses to the trial were anonymous. The patients who agreed to participate were required to provide written consent prior to commencing the study. The current trial is registered to the center of clinical trial registration of China. (registration number, ChiCTR-TRC-12001928).

Participant recruitment. From February to September 2012, participants were randomly recruited from outpatients in the Traditional Chinese Medicine Hospital affiliated with Xinjiang Medical University (Ürümqi, China). Male and female patients were included in the study in accordance with the following inclusion criteria: Aged between 40 and 80 years; received certain conventional therapies (as displayed in Table II); and willingness to participate in the study voluntarily having signed an informed consent. Patients were also required to meet the diagnostic criteria for stable COPD, which was as follows: Stable symptoms such as cough, sputum production or breathlessness for 4-6 weeks with no AE; and lung function measurements of forced expiratory volume in $1 \mathrm{sec} /$ forced vital capacity (FEV1/FVC) $\leq 70 \%$ following the use of bronchodilators. Patients were excluded based on the following: Presence of pneumothorax, pleural effusion, lung cancer, pulmonary tuberculosis, or other severe pulmonary disease; severe cardiovascular disease, liver or kidney diseases, or hematopoietic diseases; an alanine transaminase (ALT) or aspartate transaminase (AST) value higher than the upper limit of the normal value by $\mathrm{x} 1.5$; had a psychiatric disease; pregnant or in lactation; had an allergic constitution or multi-medicine allergy; were currently undergoing treatment for a tumor; had a congenital or acquired immunodeficiency; or had participated in a clinical trials within the previous month. According to the COPD assessment test (CAT) score values obtained during preliminary assessments and accounting for an $\sim 25 \%$ dropout rate, the sample size was determined by using the superiority test on two groups of quantitative data $(\alpha=0.05, \beta=0.20, \delta=4)$.

Intervention. The Yiqigubiao pill (YQGB) was prepared using the concentrated liquid from a decoction of 13 Chinese herbs (Table I). The Yiqigubiao pill and placebo $(\mathrm{Pb})$ were produced by Sinopharm Xinjiang Pharmaceutical Co., Ltd. (Ürümqi, China) in the form of a $0.19 \mathrm{~g} /$ pill. The participants were administered a 6-month cycle of conventional therapy in addition to an oral dose of the Yiqigubiao pill (YQGB group) or placebo ( $\mathrm{Pb}$ group) at a dosage of 10 pills each time, 3 times daily in the initial 3 months. The conventional therapy for individual patients was determined according to the therapeutic strategy for stable COPD recommended in the 2011 version of the GOLD (Table II) (4). The intervention was not initiated until the participants' symptoms were stable for 4-6 weeks following the administration of conventional therapy which was maintained throughout the trial. No other non-study herb for COPD was administered during the trial. The follow-up visits were offered for on a one-per-month basis during the 3-month intervention and at the end of the first and the third months after the intervention. In the follow-up visits, the acute exacerbation and adverse events were recorded. The pulmonary functions were evaluated. The Modified Medical Research Council (MMRC) dyspnea score and 6-min walk distance (6MWD) were performed. The value of CAT and the body mass index, obstruction, dyspnea and exercise (BODE) index were evaluated. 
Table I. Primary components of the Yiqigubiao pill.

Chinese name (pinyin)

\section{Dang Shen}

Fu Xiao Mai

Bai Zhu

Ban Xia

Chen Pi

$\mathrm{Zi} \mathrm{Su}$

Fu Ling

Fang Feng

Yi Yi Ren

Kuan Dong Hua

Huang Qin

Chuan Bei Mu

$\mathrm{Pi} \mathrm{Pa} \mathrm{Ye}$
Latin or common name

Amount (g)

$\begin{array}{lr}\text { Salvia miltiorrhiza } \text { Bunge } & 10 \\ \text { Blighted wheat } & 12 \\ \text { Atractylodes macrocephala Koidz } & 7 \\ \text { Pinellia ternata } & 5 \\ \text { Citrus reticulata Blanco } & 9 \\ \text { Perilla frutescens (L.) Britt. } & 7 \\ \text { Poria cocos (Schw.) Wolf } & 7 \\ \text { Saposhnikovia divaricata } \text { (Trucz.) Schischk. } & 7 \\ \text { Coix lacryma-jobi L. war.ma-yuen (Roman.) Stapf } & 12 \\ \text { Tussilago farfara L. } & 7 \\ \text { Scutellaria baicalensis Georgi } & 7 \\ \text { Fritillaria cirrhosa D. Don } & 7 \\ \text { Eriobotrya japonica } \text { (Thunb.) Lindl. } & 7\end{array}$

Table II. Conventional treatment for chronic obstructive pulmonary disease according to the recommendations in Chronic Obstructive Lung Disease (version 2011).

\begin{tabular}{llll}
\hline Strategy & \multicolumn{1}{c}{ First choice } & \multicolumn{1}{c}{ Substitution } & Others \\
\hline A & SAMA prn or SABA prn & $\begin{array}{l}\text { LAMA or LABA } \\
\text { or SABA + SAMA }\end{array}$ & Theophylline \\
B & LAMA or LABA & LAMA + LABA & Theophylline SABA +/or SAMA \\
C & ICS + LABA or LAMA & TAB + LAMA & Theophylline SABA +/or SAMA \\
& ICS + LABA or LAMA & ICS + LABA + PDE4-I & Theophylline \\
D & & LAMA + PDE4-I & SABA +/or SAMA \\
& & ICS + LAMA & Carbocisteine \\
\hline
\end{tabular}

SABA, short acting $\beta 2$-receptor agonist; SAMA, short acting anticholinergic drug; prn, as needed; LABA, long acting $\beta 2$-receptor agonist; LAMA, long acting anticholinergic drug; ICS, inhaled glucocorticoid; PDE4-I, phosphodiesterase-4 inhibitor.

Diagnostic criteria and treatment for AECOPD. The diagnostic criteria for AECOPD included the exacerbation of original symptoms or the emergence of new symptoms lasting $\geq 3$ days. The symptoms observed include coughing, sputum or purulent sputum production, wheezing and dyspnea, all of which required additional intervention. In the case of $\mathrm{AE}$, the intervention of the trial was temporarily ceased and the participant was provided with extramural hospital treatment or hospitalization depending on the severity of the symptoms, which were diagnosed according to the classification and treatment strategy for the AE of COPD recommended in the GOLD (version 2011). The extramural hospital treatments included increasing the dosage and rate of the administered bronchodilator, inhalation of ipratropium bromide or tiotropium bromide if not previously administered, or the delivery of antibiotics if the patient had fever or increased production of sputum or purulent sputum. The aforementioned participants were hospitalized if their symptoms regressed rapidly with regard to sudden breathing difficulties when at rest, the emergence of new symptoms or the aggravation of the original symptoms (such as cyanosis and peripheral edema), recent arrhythmia, or if the extramural hospital treatments failed. The relief of AECOPD was assessed according to the guidelines for the diagnosis and treatment of COPD recommended in the GOLD (version 2011). After the AE was relieved, the intervention of the trial was continued.

Outcome measures. The original data of the current clinical trial were recorded in the case report form (CRF), entered and managed in an Electronic Data Capture system. Spot checks on electric record conducted by the Steering Committee ensured the completion of and the conformance to the CRF.

Primary outcome was measured by an evaluation of the therapeutic effects as determined by the occurrence or absence of AECOPD. The secondary outcome measures included: i) Lung function; 6MWD test, MMRC dyspnea score, CAT score and BODE score, all of which were measured prior to and at the $1 \mathrm{st}, 2 \mathrm{nd}, 3 \mathrm{rd}, 4$ th and 6 th months of the trial; 
ii) determination of the percentage of blood inflammatory cells and the level of inflammatory factors, arterial blood gas analysis and safety indexes such as routine blood tests, urine and stool analysis, hepatic (ALT and AST) and renal (blood urea nitrogen and creatinine) function assessments, and electrocardiography, all of which were performed prior to and during the 3rd month of the trial; iii) the recording of all adverse events that occurred during the trial period.

Evaluation of therapeutic effects. The occurrence of AE was used as a determinant of the therapeutic effects. Briefly, the following parameters were recorded: Time from the initial intervention to the first $\mathrm{AE}$; the number of AEs (one account of $\mathrm{AE}$ was classified as the occurrence of AE twice within 5 days); and the severity and duration of AE. The severity of AECOPD was scored according the guidelines recommended by the American Thoracic society/European Respiratory Society as level I, treatment at home; level II, requiring hospitalization; and level III, leading to respiratory failure (26).

Lung function measurement. For the evaluation of lung function, the values of the parameters FEV1/FVC, FEV1, FVC, $\% \mathrm{FVC}$ and FEV1\% were measured with a KoKo Spirometer (nSpire Health, Inc., Longmont, CO, USA) following the inhalation of bronchodilator (300 $\mu \mathrm{g}$ albuterol sulfate inhalation aerosol; Glaxo Wellcome, S.A., Aranda de Duero, Spain).

6MWD assessment. The 6MWD test was performed according to a previous report (27) along a 30-m corridor. The participants rested on a chair for $\geq 10 \mathrm{~min}$ prior to the assessment. The values for pulse, blood pressure, heart rate and oxygen saturation were measured, and the Borg Scale score and general fatigue levels were evaluated prior to and after the assessment.

MMRC dyspnea score. The participants received a dyspnea score as described by the British MMRC, in accordance with the methods mentioned previously (28). The MMRC provides a 1-5 grade scale with regards to various physical activity: i) Grade 0 , no obvious difficulty breathing, except during intense activities; ii) grade 1, breathlessness on brisk walking or on walking up a slope; iii) grade 2 , slower walking than peers due to breathing difficulty or having to pause for breath when walking on flat ground at normal speed; iv) grade 3 , the patient is required to pause for breath during a 100-m walk or after a few minutes of walking on flat ground; and v) grade 4, the patient is unable to leave the house as a result of significant breathing difficulties, or experiences shortness of breath when changing clothes.

CAT score. A CAT was performed as previously described (29). The participants were asked to complete a CAT questionnaire that consisted of 8 questions involving scoring 0 to 5 according to their health status.

BODE score. BODE score was used to predict the mortality of the patients (30). The BODE index was obtained by evaluating the body mass index, the degree of airflow obstruction, dyspnea score and exercise capacity with a multidimensional 10-point scale. The body mass index (B) was calculated with a formula BMI = body weight $(\mathrm{kg}) /$ square of body height $\left(\mathrm{m}^{2}\right)$
( score $=0$ if BMI $>21 \mathrm{~kg} / \mathrm{m}^{2}$; score $=1$ if BMI $\left.\leq 21 \mathrm{~kg} / \mathrm{m}^{2}\right)$. The degree of airflow obstruction $(\mathrm{O})$ was assessed by the value of FEV1\% (score $=0$ if $\geq 65$, score $=1$ if $=50-64$, score $=2$ if $=36-49$ and score $=3$ if $\leq 35$ ). The dyspnea score (D) was based on MMRC score (score $=0$ for MMRC level 0-1; scores = 1, 2 and 3 corresponded to MMRC levels 2, 3 and 4, respectively). Exercise capacity (E) was evaluated by $6 \mathrm{MWD}$ (score $=0$ for $6 \mathrm{MWD} \geq 350 \mathrm{~m}$, score $=1$ for $6 \mathrm{MWD}=250-349 \mathrm{~m}$, score $=2$ for $6 \mathrm{MWD}=150-249 \mathrm{~m}$ and score $=3$ for $6 \mathrm{MWD} \leq 149 \mathrm{~m})$. A higher BODE index was considered to indicate a higher risk of succumbing to the disease.

Flow cytometry analysis. The preparation and flow cytometric analysis of peripheral blood mononuclear cells (PBMCs) were performed as previously described (31). PBMCs from heparinized blood were separated by Ficoll/Histopaque density gradient centrifugation (Sigma; Merck Millipore, Darmstadt, Germany) and cryopreserved in fetal calf serum containing $10 \%$ dimethyl sulfoxide using a slow temperature-lowering method. Cells were stored in liquid nitrogen prior to thawing. The freshly thawed PBMCs were surface stained with fluorescein isothiocyanate (FITC) mouse anti-human CD4 antibody, clone RPA-T4 (1:5; cat. no. 555346; BD Biosciences, Franklin Lakes, NJ, USA) and PE-Cy ${ }^{\mathrm{TM}} 7$ mouse anti-human CD8, clone RPA-T8 (1:20; cat. no. 557746; BD Biosciences) antibodies. After washing and fixing with $0.2 \%$ paraformaldehyde in phosphate-buffered saline, total $\mathrm{CD}^{+}{ }^{+}$and $\mathrm{CD} 8^{+}$cells were counted using a Guava easyCyte $8 \mathrm{HT}$ flow cytometer (EMD Millipore, Billerica, MA, USA) and analyzed with Guavasoft version 2.5 software. The populations were expressed as a percentage of the total PBMCs.

ELISA. Sera samples were separated from peripheral venous blood. The measurements of the concentration levels of interleukin (IL)-6, IL-8 and tumor necrosis factor (TNF)- $\alpha$ in serum were performed with ELISA kits [IL-6 (h) ELISA kit (EK0410); IL-8 (h) ELISA kit (EK0413); TNF $\alpha$ (h) ELISA kit (EK0525); Boster Biological Technology, Ltd., Wuhan, China) according to the manufacturer's instructions. Briefly, serum was added to the ready-to-use ELISA plate and incubated for $90 \mathrm{~min}$ at $37^{\circ} \mathrm{C}$. After washing with PBS containing $0.5 \%$ Tween-20, biotin-conjugated detection antibody was added to the plate, which was then incubated for $60 \mathrm{~min}$ at $37^{\circ} \mathrm{C}$. Following a second wash, the plate was incubated with avidin-biotin complex. After a third wash, 3,3',5,5'-tetramethylbenzidine buffer was added and the plate was incubated at room temperature for $15 \mathrm{~min}$. Stop solution was then added to each well and the absorbance was read at $450 \mathrm{~nm}$. The serum concentration of each cytokine was calculated according to a standard curve.

Arterial blood gas analysis. Arterial blood gas analysis was performed prior to and after the 3-month intervention on a GEM Premier 3000 (Instrumentation Laboratory, Bedford, MA, USA). The values of arterial acidity $(\mathrm{pH})$, oxygen tension $\left(\mathrm{PaO}_{2}\right)$, carbon dioxide tension $\left(\mathrm{PaCO}_{2}\right)$ and oxyhemoglobin saturation $\left(\mathrm{SaO}_{2}\right)$ were measured.

Randomization and blinding. The current study was conducted as a randomized, double-blind, placebo-controlled 
trial. Participants were randomly allocated into two groups: A YQGB group and a $\mathrm{Pb}$ group. The randomization was computerized using an Interactive Web Response System (also known as IWRS), which generated a list of codes assigned to each participant. Participants in the YQGB and $\mathrm{Pb}$ groups received conventional therapy, as listed in Table II, in addition to the Yiqigubiao pill or matching placebo, respectively. An emergency envelope was prepared for each participant within which the file containing the randomization code was enclosed and sealed, in addition to the group allocation and the therapy to be administered in the trial. The emergency letter was kept with the intervention drug, and only opened in the case of severe adverse events or an emergency, until the trial had terminated. The participant was considered as a dropout if the emergency letter had been opened without cause.

The Yiqigubiao pill and the placebo were packaged in identical plastic bottles, numbered sequentially and distributed to the participants according to their randomization code. Outcome measurements were performed and statistically analyzed by an independent person who did not participate in any other section of the trial. Participants and investigators were blinded to the treatment status until the trial had terminated.

Statistical analysis. The data are presented as the mean \pm standard deviation and were analyzed using the Statistical Analysis System software (version 9.3; SAS Institute Inc., Cary, NC, USA) by two independent samples t-test. Fisher's exact test was used to compare the severity of the first AECOPD. A $\chi^{2}$ test for the contingency table was used to compare the gender, duration of smoking history and educational background. Welch's test was used to analyze the scores of MMRC and BODE. $\mathrm{P}<0.05$ was considered to indicate a statistically significant difference.

\section{Results}

Study participants. All participants were recruited from outpatients in the Traditional Chinese Medicine Hospital affiliated with Xinjiang Medical University from February to September 2012. A total of 171 patients were eligible to participate in the study and were randomly allocated into the YQGB $(\mathrm{n}=84)$ or $\mathrm{Pb}$ group ( $\mathrm{n}=87$; Fig. 1). The demographics of the participants are presented in Table III. No differences in patient characteristics were observed between the two groups. During the 3-month intervention, 14/84 participants in the YQGB group and $18 / 87$ participants in the $\mathrm{Pb}$ group withdrew for various reasons. In the 3-month post-intervention follow-up visit, 3/70 participants in the YQGB group and 4/69 participants in the $\mathrm{Pb}$ group withdrew from the trial. Finally, the population that completed the 6-month study duration, 67 in the YQGB group and 65 in the $\mathrm{Pb}$ group, underwent evaluation for all parameters. The 39 excluded participants underwent a therapeutic effects evaluation based on the occurrence of $\mathrm{AE}$ and other evaluations depending on the stage of the trial they had reached.

Occurrence of AECOPD. In order to evaluate the effects of Yiqigubiao pill in terms of aiding COPD treatment, the current study compared the status of AE occurrence in the two groups. Of the 84 patients in the YQGB group, 29 had AE with an incidence rate of $0.35 \pm 0.48 \mathrm{AEs} / 6$ months, whereas $68 / 87$ patients
Table III. Baseline characteristics of the enrolled patients.

\begin{tabular}{|c|c|c|}
\hline Factors & YQGB $(n=84)$ & $\mathrm{Pb}(\mathrm{n}=87)$ \\
\hline Age, years & $67.32 \pm 1.17$ & $65.74 \pm 1.15$ \\
\hline Course of COPD, years & $16.15 \pm 12.80$ & $16.85 \pm 14.36$ \\
\hline \multicolumn{3}{|l|}{ Gender, $\mathrm{n}(\%)^{\mathrm{a}}$} \\
\hline Male & $52(61.9)$ & $58(66.67)$ \\
\hline Female & $32(38.10)$ & $29(33.33)$ \\
\hline \multicolumn{3}{|l|}{ Smoking history, $\mathrm{n}(\%)^{\mathrm{a}}$} \\
\hline Yes & $53(63.1)$ & $60(68.97)$ \\
\hline No & $31(36.9)$ & $27(31.03)$ \\
\hline \multicolumn{3}{|l|}{ Higher education $^{\mathrm{a}}$} \\
\hline No, n $(\%)$ & $66(79.6)$ & $80(77.0)$ \\
\hline Yes, n (\%) & $18(21.4)$ & $20(23.0)$ \\
\hline \multicolumn{3}{|l|}{ Lung function } \\
\hline FEV1 & $1.31 \pm 0.52$ & $1.43 \pm 0.65$ \\
\hline $\mathrm{FVC}$ & $2.37 \pm 0.78$ & $2.43 \pm 0.84$ \\
\hline FEV $1 \%$ & $53.26 \pm 18.63$ & $57.32 \pm 22.95$ \\
\hline$\% \mathrm{FVC}$ & $74.45 \pm 17.98$ & $76.28 \pm 21.40$ \\
\hline FEV1/FVC & $55.25 \pm 11.47$ & $57.37 \pm 10.73$ \\
\hline \multicolumn{3}{|l|}{ Life quality } \\
\hline Body mass index & $24.17 \pm 3.50$ & $24.90 \pm 3.60$ \\
\hline CAT & $14.95 \pm 7.27$ & $14.91 \pm 8.07$ \\
\hline 6MWD (m) & $387.96 \pm 86.06$ & $404.89 \pm 89.33$ \\
\hline MMRC dyspnea score & $1.56 \pm 0.77$ & $1.56 \pm 1.09$ \\
\hline BODE index & $2.58 \pm 1.77$ & $2.49 \pm 2.40$ \\
\hline
\end{tabular}

Data are presented as mean \pm standard deviation and analyzed with two independent sample t-tests. ${ }^{\text {a }}$ Data were analyzed using the $\chi^{2}$ test for contingency table. YQGB, Yiqigubiao pill; Pb, placebo; COPD, chronic obstructive pulmonary disease; FEV1, forced expiratory volume in $1 \mathrm{sec}$; FVC, forced vital capacity; CAT, COPD assessment test; 6MWD, 6-min walking distance; MMRC, Modified Medical Research Council; BODE, body mass index, obstruction, dyspnea and exercise.

in the $\mathrm{Pb}$ group had $\mathrm{AE}$, resulting a higher incidence rate of $1.77 \pm 1.22 \mathrm{AEs} / 6$ months $(\mathrm{P}<0.01)$.

With regard to the time interval from the initial intervention to the first AE occurrence, it was observed to be $144.21 \pm 52.63$ days in the YQGB group, indicating that all cases of first AE occurred after the 3-month intervention, compared with $66.53 \pm 39.69$ days $(\mathrm{P}<0.01)$ in the $\mathrm{Pb}$ group, which indicated that the majority of first AEs occurred within the 3-month intervention. Considering the treatments administered for AE resulted in additional intervention effects to the study, only severity and duration of the first AE were evaluated. The results indicated that the duration in the YQGB group was 5.62 \pm 2.67 days, compared with $9.10 \pm 4.37$ days in the $\mathrm{Pb}$ group $(\mathrm{P}<0.01)$. For the evaluation of severity, all AE cases were defined as level I or II, and no exacerbation developed into level III. Furthermore, no difference existed in terms of severity between the two groups (Table IV). Accordingly, the results suggest that the Yiqigubiao pill is an efficient therapy in promoting COPD treatment by decreasing the exacerbation and duration of AE. 


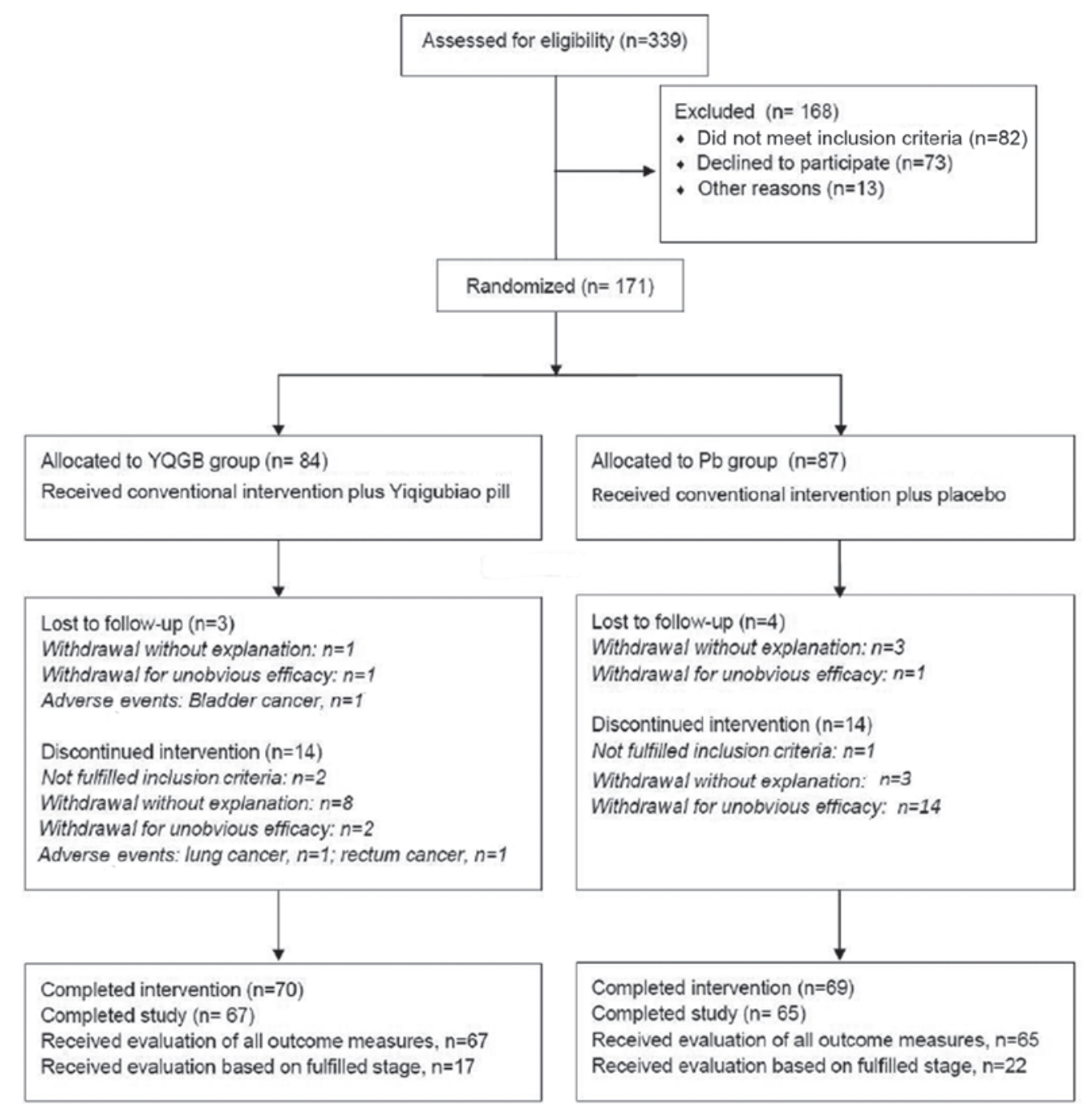

Figure 1. Flow chart displaying the participation throughout the study process. YQGB, Yiqigubiao pill; Pb, placebo.

Lung functions, 6MWD and scores of MMRC, CAT and $B O D E$. The lung functions were measured prior to and throughout the 6-month study. The values of FEV1\% and $\% \mathrm{FVC}$, which are indicative of lung function, increased and reached the summits after 2 months intervention and declined thereafter. The changes in FEV1\% and \% FVC were consistent between the YQGB and $\mathrm{Pb}$ group throughout the study. The value of FEV1/FVC remained consistent in the two groups (Fig. 2A). By calculating the mean difference of lung function-associated parameters prior to and following the intervention of the study, greater improvements of FEV1, FVC, FEV1\% and \%FVC tended to be observed in the YQGB group, although these improvements were not statistically different when compared with those in the $\mathrm{Pb}$ group (Table V).

Although the Yiqigubiao pill did not demonstrate marked effects in terms of improving lung function, the physical capacity indicated by the 6MWD results and the life quality assessed by the CAT score were improved throughout the study, and significantly in those patients from the YQGB group within the 3-month intervention period, and remained higher compared with patients from the $\mathrm{Pb}$ group in the subsequent 3-months without intervention involving the Yiqigubiao pill or the placebo (Fig. 2B). In addition, a marked improvement in terms of 6MWD results, and declines in scores of MMRC, CAT and BODE were observed in the YQGB group as early as 2 months after intervention ( $\mathrm{P}<0.05$; data not shown). The differences between the two group increased after the 3-month intervention, and were maintained until the end of the study $(\mathrm{P}<0.01$; Table $\mathrm{V})$.

Inflammatory responses and arterial blood gas analysis. In order to assess the effects of the Yiqigubiao pill on the systemic inflammatory responses incurred by COPD, the percentage of $\mathrm{CD}^{+}$and $\mathrm{CD}^{+}$cells in peripheral blood were determined, as were the levels of pro-inflammatory cytokines IL-6, IL-8 and TNF- $\alpha$ in sera prior to and after the 3 -month intervention. Prior to the current study, the values of all parameters were similar between the YQGB and $\mathrm{Pb}$ group. Compared with the placebo, the Yiqigubiao pill elicited a greater reductions in the serum levels of IL-8 and $\mathrm{TNF}-\alpha$, and in the $\mathrm{CD} 8^{+}$cell percentage, which resulted in a higher $\mathrm{CD} 4 / \mathrm{CD} 8$ value. However, the changes in $\mathrm{CD} 4^{+}$cell percentage and on the levels of IL-6 revealed no difference 
Table IV. Primary characteristics of AECOPD.

\begin{tabular}{|c|c|c|c|c|}
\hline Index & YQGB (n=84) & $\mathrm{Pb}(\mathrm{n}=87)$ & Statistic & P-value \\
\hline Exacerbation cases, $\mathrm{n}(\%)^{\mathrm{a}}$ & $29(34.5)$ & $68(78.2)$ & 33.25 & $<0.01$ \\
\hline Interval to the first AE (days) & $144.21 \pm 52.63$ & $66.53 \pm 39.69$ & -7.03 & $<0.001$ \\
\hline Duration (days) & $5.62 \pm 2.67$ & $9.10 \pm 4.37$ & -3.98 & $<0.001$ \\
\hline \multicolumn{5}{|l|}{ Severity, $\mathrm{n}(\%)^{\mathrm{b}}$} \\
\hline Level I & $26(89.66)$ & $64(94.12)$ & - & 0.437 \\
\hline Level II & $3(10.34)$ & $4(5.88)$ & & \\
\hline Incidence rate (AEs/6 months) & $0.35 \pm 0.48$ & $1.77 \pm 1.22$ & -10.14 & $<0.001$ \\
\hline
\end{tabular}

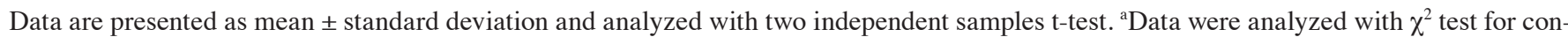
tingency table. ${ }^{b}$ Data were analyzed with Fisher's exact test. AECOPD, acute exacerbation chronic obstructive pulmonary disease; YQGB, Yiqigubiao pill; $\mathrm{Pb}$, placebo.

Table V. Evaluations on lung functions and life quality.

\begin{tabular}{|c|c|c|c|c|c|c|c|c|}
\hline \multirow[b]{2}{*}{ Parameter } & \multicolumn{2}{|c|}{ 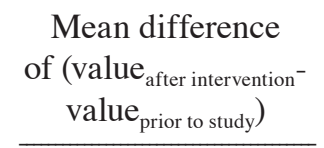 } & \multirow[b]{2}{*}{ Statistic } & \multirow[b]{2}{*}{ P-value } & \multicolumn{2}{|c|}{$\begin{array}{l}\text { Mean difference } \\
\text { of (value } \\
\text { valuer study }_{\text {prior to study }} \text { ) }\end{array}$} & \multirow[b]{2}{*}{ Statistic } & \multirow[b]{2}{*}{ P-value } \\
\hline & $\begin{array}{l}\text { YQGB } \\
(n=70)\end{array}$ & $\begin{array}{c}\mathrm{Pb} \\
(\mathrm{n}=69)\end{array}$ & & & $\begin{array}{l}\text { YQGB } \\
(n=67)\end{array}$ & $\begin{array}{c}\mathrm{Pb} \\
(\mathrm{n}=65)\end{array}$ & & \\
\hline \multicolumn{9}{|l|}{ Lung function } \\
\hline FEV1 & 0.06 & 0.01 & -1.174 & 0.243 & 0.06 & -0.03 & -1.601 & 0.112 \\
\hline $\mathrm{FVC}$ & 0.13 & 0.03 & -1.326 & 0.187 & 0.15 & 0.06 & -1.082 & 0.281 \\
\hline FEV1\% & 2.89 & 0.42 & -1.342 & 0.182 & 2.58 & -1.57 & -1.768 & 0.080 \\
\hline$\% \mathrm{FVC}$ & 4.46 & 0.93 & -1.564 & 0.120 & 5.63 & 1.77 & -1.513 & 0.133 \\
\hline FEV1/FVC & 0.10 & -0.09 & -0.156 & 0.88 & -1.33 & -2.14 & -0.603 & 0.548 \\
\hline \multicolumn{9}{|l|}{ Life quality } \\
\hline CAT & -6.99 & 3.14 & 11.617 & $<0.001$ & -6.03 & 2.63 & 8.486 & $<0.001$ \\
\hline 6MWD & 41.63 & -37.10 & -9.898 & $<0.001$ & 31.05 & -34.67 & -8.443 & $<0.001$ \\
\hline MMRC dyspnea score ${ }^{a}$ & $0(-1,0)$ & $0(0,1)$ & 33.468 & $<0.001$ & $0(-1,0)$ & $0(0,1)$ & 24.298 & $<0.001$ \\
\hline $\mathrm{BODE}^{\mathrm{a}}$ & $-0.5(-1,0)$ & $0(0,1)$ & 24.505 & $<0.001$ & $0(-1,0)$ & $0(0,1)$ & -15.935 & $<0.001$ \\
\hline
\end{tabular}

Data were analyzed with two independent samples t-test and the mean values are presented. aData were analyzed with a Welch test and presented as quartiles. YQGB, Yiqigubiao pill; Pb, placebo; FEV1, forced expiratory volume in $1 \mathrm{sec}$; FVC, forced vital capacity; CAT, chronic obstructive pulmonary disease assessment test; 6MWD, 6-min walking distance; MMRC, Modified Medical Research Council; BODE, body mass index, obstruction, dyspnea and exercise.

between the YQGB and $\mathrm{Pb}$-treated groups following the intervention (Table VI).

In the present study, arterial blood gas analysis was performed prior to and following the 3-month intervention. The levels of all parameters, including the $\mathrm{pH}$ value and the values of $\mathrm{PaO}_{2}, \mathrm{PaCO}_{2}$ and $\mathrm{SaO}_{2}$ in the arterial blood, remained unchanged from pre-treatment levels after the 3-month intervention in the two groups (Table VI).

Safety variables and adverse events. Comparing the results of the $\mathrm{Pb}$ group obtained prior to and following intervention, the conventional therapy for COPD did not alter vital signs including heart rate, respiration rate, body temperature and blood pressure (data not shown). Furthermore, the Yiqigubiao pill did not affect vital signs, as no difference was observed between results obtained prior to and those obtained following the intervention in the YQGB group (data not shown), or in following comparison of the results from the YQGB and $\mathrm{Pb}$ group retrieved after the intervention (Table VII). Furthermore, the Yiqigubiao pill did not alter the results of routine blood, urine and stool tests, the electrocardiography, or the tests for hepatic and renal functions (data not shown). There were 12 adverse events recorded during the 6-month study, six in the YQGB group and six in the $\mathrm{Pb}$ group (Table VIII). The adverse events were not associated with the intervention. 
Table VI. Parameters on inflammation and arterial blood gas analysis prior to and after three-month intervention.

\begin{tabular}{|c|c|c|c|c|c|c|c|c|}
\hline \multirow[b]{2}{*}{ Parameter } & \multicolumn{2}{|c|}{ Prior to intervention ${ }^{\mathrm{a}}$} & \multirow[b]{2}{*}{$\mathrm{t}$} & \multirow[b]{2}{*}{ P-value } & \multicolumn{2}{|c|}{ After intervention ${ }^{\mathrm{b}}$} & \multirow[b]{2}{*}{$\mathrm{t}$} & \multirow[b]{2}{*}{ P-value } \\
\hline & YQGB (n=74) & $\mathrm{Pb}(\mathrm{n}=76)$ & & & YQGB $(n=56)$ & $\mathrm{Pb}(\mathrm{n}=62)$ & & \\
\hline $\mathrm{CD}^{+}$cells in blood $(\%)$ & $38.12 \pm 12.41$ & $38.90 \pm 14.03$ & 0.357 & 0.721 & $3.83 \pm 17.80$ & $-1.97 \pm 17.63$ & -1.775 & 0.079 \\
\hline $\mathrm{CD}^{+}$cells in blood $(\%)$ & $48.88 \pm 15.95$ & $47.63 \pm 14.55$ & -0.502 & 0.617 & $-12.41 \pm 20.85$ & $2.07 \pm 17.40$ & 4.070 & $<0.001$ \\
\hline CD4/CD8 & $0.94 \pm 0.58$ & $0.98 \pm 0.64$ & 0.350 & 0.727 & $0.32 \pm 0.82$ & $-1.67 \pm 0.80$ & -3.26 & 0.002 \\
\hline IL-6 in serum $(\mathrm{pg} / \mathrm{ml})$ & $9.36 \pm 10.43$ & $8.73 \pm 10.51$ & -0.370 & 0.712 & $-0.30 \pm 8.33$ & $0.97 \pm 11.78$ & 0.680 & 0.498 \\
\hline IL-8 in serum (pg/ml) & $4.06 \pm 5.15$ & $3.21 \pm 5.47$ & -0.979 & 0.329 & $-1.46 \pm 2.78$ & $1.71 \pm 10.45$ & 2.303 & 0.024 \\
\hline TNF- $\alpha$ in serum (pg/ml) & $8.31 \pm 5.03$ & $8.03 \pm 7.59$ & -0.266 & 0.791 & $-1.95 \pm 6.60$ & $5.00 \pm 7.85$ & 5.223 & $<0.001$ \\
\hline \multicolumn{9}{|l|}{ Arterial blood gas analysis } \\
\hline $\mathrm{PaO}_{2}(\mathrm{mmHg})$ & $76.05 \pm 18.34$ & $75.77 \pm 19.19$ & 0.092 & 0.927 & $3.48 \pm 22.73$ & $-2.89 \pm 24.16$ & 1.295 & 0.199 \\
\hline $\mathrm{PaCO}_{2}(\mathrm{mmHg})$ & $40.86 \pm 9.05$ & $40.15 \pm 8.13$ & 0.504 & 0.615 & $-1.41 \pm 5.88$ & $0.02 \pm 8.99$ & -0.903 & 0.369 \\
\hline $\mathrm{SaO}_{2}(\%)$ & $93.34 \pm 8.05$ & $94.15 \pm 3.61$ & -0.785 & 0.434 & $0.54 \pm 5.74$ & $0.40 \pm 4.77$ & 0.852 & 0.397 \\
\hline
\end{tabular}

All data are presented as mean \pm standard deviation. a Data were analyzed with two independent samples t-tests. ${ }^{b}$ Data were obtained by subtracting the value obtained prior to intervention from the value obtained after intervention, and were analyzed with t-tests to assess the difference in means. IL, interleukin; TNF, tumor necrosis factor; YQGB, Yiqigubiao pill; $\mathrm{Pb}$, placebo; $\mathrm{PaO}_{2}$, oxygen tension; $\mathrm{PaCO}$, carbon dioxide tension; $\mathrm{SaO}_{2}$, oxyhemoglobin saturation.

Table VII. Parameters of vital signs prior to and after 3-month intervention.

\begin{tabular}{|c|c|c|c|c|c|c|c|c|}
\hline \multirow[b]{2}{*}{ Parameter } & \multicolumn{2}{|c|}{ Prior to intervention } & \multirow[b]{2}{*}{$\mathrm{t}$} & \multirow[b]{2}{*}{ P-value } & \multicolumn{2}{|c|}{ After intervention } & \multirow[b]{2}{*}{$\mathrm{t}$} & \multirow[b]{2}{*}{ P-value } \\
\hline & $\begin{array}{l}\text { YQGB } \\
(n=84)\end{array}$ & $\begin{array}{c}\mathrm{Pb} \\
(\mathrm{n}=87)\end{array}$ & & & $\begin{array}{l}\text { YQGB } \\
(n=70)\end{array}$ & $\begin{array}{c}\mathrm{Pb} \\
(\mathrm{n}=69)\end{array}$ & & \\
\hline Heart rate & $77.52 \pm 9.98$ & $78.47 \pm 9.89$ & 0.62 & 0.53 & $79.31 \pm 10.01$ & $78.37 \pm 11.02$ & 0.62 & 0.53 \\
\hline Respiration rate & $19.00 \pm 1.53$ & $18.91 \pm 1.55$ & 0.39 & 0.69 & $18.94 \pm 1.28$ & $18.817 \pm 1.32$ & 0.58 & 0.56 \\
\hline Body temperature $\left({ }^{\circ} \mathrm{C}\right)$ & $36.54 \pm 0.18$ & $36.50 \pm 0.18$ & 1.65 & 0.10 & $36.54 \pm 0.17$ & $36.49 \pm 0.15$ & 1.74 & 0.08 \\
\hline \multicolumn{9}{|l|}{ Blood pressure } \\
\hline Systolic (mmHg) & $126.87 \pm 9.31$ & $128.26 \pm 10.33$ & 0.92 & 0.36 & $127.16 \pm 6.99$ & $127.56 \pm 8.52$ & 0.92 & 0.36 \\
\hline Diastolic (mmHg) & $75.88 \pm 7.54$ & $77.59 \pm 8.80$ & 1.37 & 0.17 & $74.46 \pm 5.66$ & $73.60 \pm 6.30$ & 1.37 & 0.17 \\
\hline
\end{tabular}

Data are presented as mean \pm standard deviation and were analyzed with two independent samples t-test. YQGB, Yiqigubiao pill; Pb, placebo

\section{Discussion}

COPD is a pulmonary disease that develops chronically and leads to the decline of lung function and life quality, and ultimately a number of patients succumb to the disease. For stable COPD patients, the lung function deficit and decline in the quality of life are largely attributed to recurrent AE (32). However, the predominant therapies employed in clinical COPD treatment, such as bronchodilators and inhaled or orally administered corticosteroids, are unable to efficiently prevent the decline in lung function. For example, in previous studies, the reduction in the FEV1 value was $41 \mathrm{ml} /$ year in patients treated with tiotropium, compared with $42 \mathrm{ml} /$ year in a placebo group and 47-69 ml/year in non-treated patients $(33,34)$. Furthermore, the aforementioned therapies result in various side effects such as severe cardiovascular events, osteoporosis and cataracts $(9,35,36)$. Therefore, the development of novel COPD therapies, particularly those able to prevent AE occurrence with minimal side effects, will be crucial for COPD treatment.

TCM has widely been applied in the treatment of chronic pulmonary diseases $(37,38)$. The Yiqigubiao pill is a Chinese herbal formula used to strengthen physical capacity, regulate immune functions and improve the health status in TCM. In the present clinical study, we proposed that the Yiqigubiao pill may be useful in COPD treatment, as the majority of COPD patients withdrawing from treatment exhibited symptoms or indicators such as abdominal distension, anorexia, excessive sweating, emaciated limbs, a decrease in body mass index and innutrition (39).

In this randomized, double-blind, placebo-controlled trial, it was revealed that the Yiqigubiao pill prolonged 


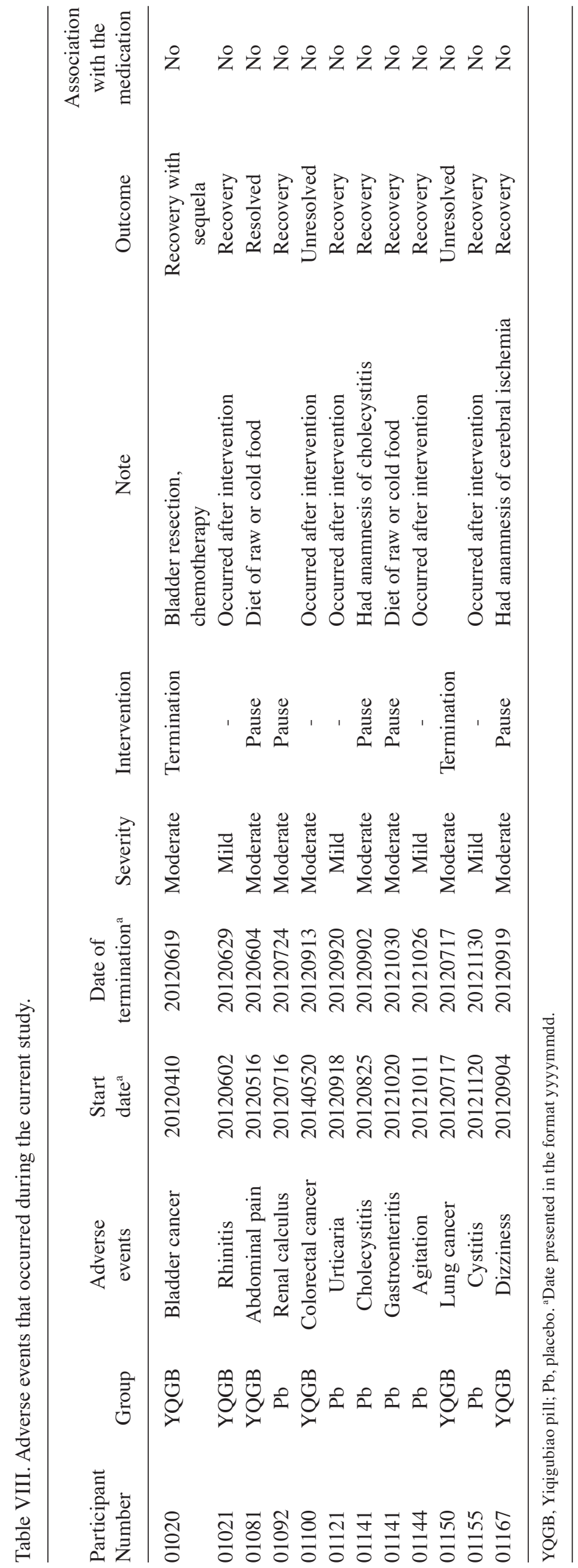


A
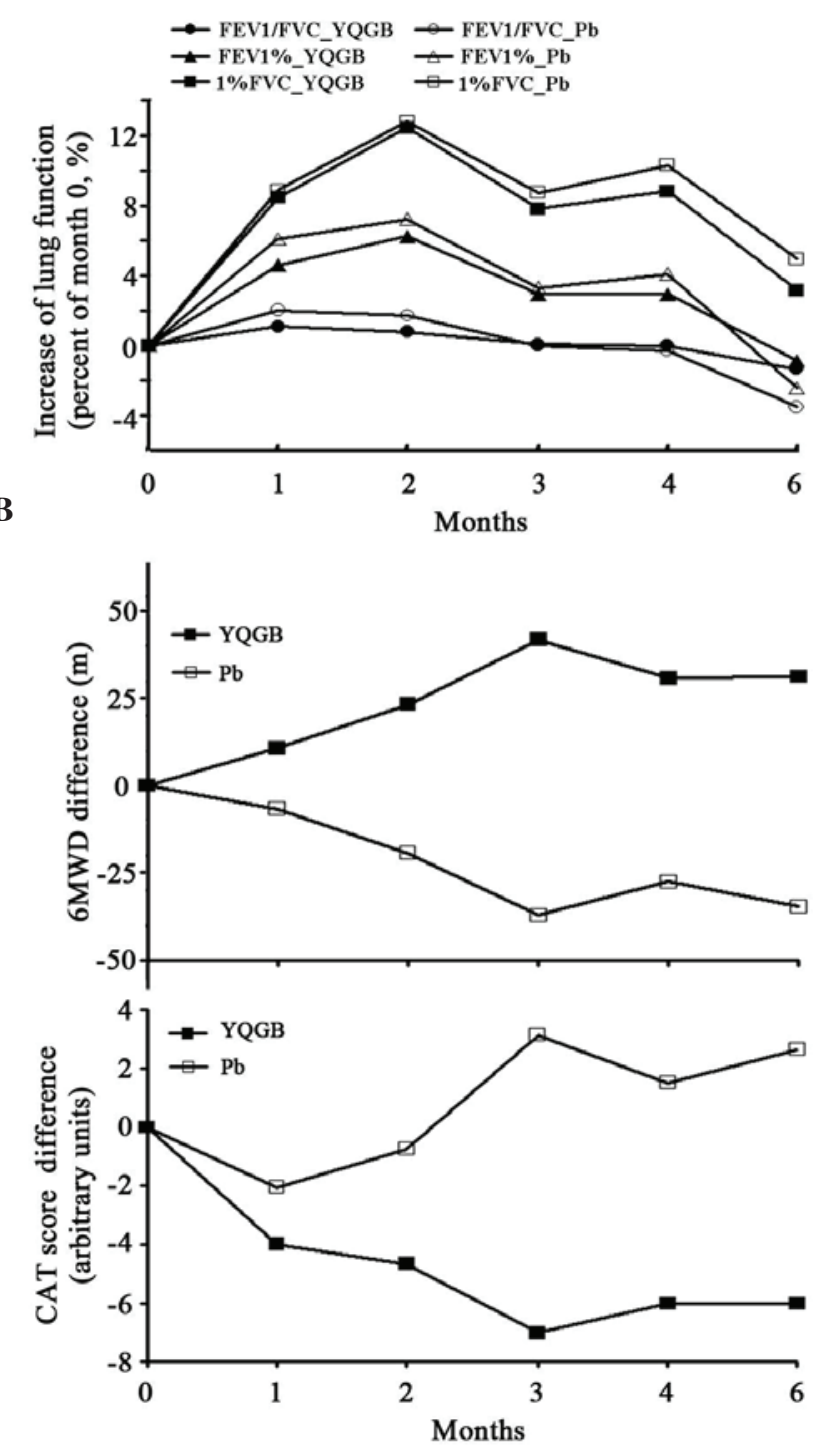

Figure 2. Lung function and life quality score throughout the 6-month study. Lung function, 6MWD and CAT score were measured prior to the study (month 0) and throughout the study (once per month). (A) Lung function parameters FEV1/FVC, FEV1\% and \%FVC. Mean differences between each time point and month 0 were calculated. (B) 6MWD and CAT score. Average differencea between the result at each time point and month 0 are peesented. YQGB, Yiqigubiao pill; Pb, placebo; FEV1, forced expiratory volume in $1 \mathrm{sec}$; FVC, forced vital capacity; 6MWD, 6-min walking distance; CAT, chronic obstructive pulmonary disease assessment test.

the interval between the initial intervention and the first $\mathrm{AE}$, reduced the duration of $\mathrm{AE}$ and therefore decreased the incidence rate of $\mathrm{AE}$ in a given period. The results of the present study showed that 55/84 (65.8\%) participants in the YQGB group had not developed AE, which was higher compared with those in $\mathrm{Pb}$ group (19/87, 21.8\%; Table IV). Typically, the symptoms of COPD such as coughing, sputum production and breathlessness, impair life quality and cause a mental burden to COPD patients and their families (40). In the present study, the Yiqigubiao pill improved the life quality and exercise endurance of the patients, which were manifested by increasing the distance reached in the $6 \mathrm{MWD}$ test and by lowering the scores of
MMRC, CAT and BODE index analyses. A lower value of BODE score was obtained in the YQGB group, which indicates an improved prognosis. The aforementioned effects were most obvious subsequent to the 3-month intervention; however, they were maintained for the next three months without intervention. Thus, this indicated that the Yiqigubiao pill was able to attenuate COPD progression, and relieve the suffering and the economic burden of the patients to a certain degree.

With regard to the effects of the Yiqigubiao pill on lung function, an significant improvement in lung function was not observed at all evaluation time-points. The current results suggest that the decrease of AE incidence and the improvement of life quality was not associated with lung function restoration. The data are similar to that of a previous report in which a poor correlation was observed between lung function and COPD symptoms, exercise endurance and the rate and severity of AE (41).

COPD may be considered an inflammatory lung disease with chronic inflammation and oxidant/antioxidant imbalance serving as the predominant characteristics (42). The levels of IL- 8 have been observed to significantly increase in bronchoalveolar lavage fluid and sputum from patients with COPD $(6,43)$. In the present study, it was determined that the decline in the percentage of $\mathrm{CD}^{+}$cells in peripheral blood and serum cytokine levels of IL- 8 and TNF- $\alpha$ were reduced following intervention with the Yiqigubiao pill, as compared with the placebo. In addition, the Yiqigubiao formula has been employed for the treatment of recurrent airway inflammation induced by flu (19). The Yiqigubiao formula, and a similar therapy termed $\mathrm{Bu} \mathrm{Qi} \mathrm{Gu}$ Biao therapy, have been used to treat allergic rhinitis $(20,44)$. The anti-inflammatory functions of the Yiqigubiao pill arise from the active ingredients of the involved herbs, a number of which have been reported to be anti-inflammatory (45-47). We propose that Yiqigubiao pill may provide supplementary benefits to the conventional therapy used in the treatment of patients with COPD in relieving inflammatory responses.

In the present study, high frequencies of exacerbation were observed in the YQGB (29/84, 34.5\%) and $\mathrm{Pb}(68 / 87,78.2 \%)$ groups (Table IV). The high incidence rate of AECOPD was likely a result of the elderly patients recruited in the present study. Elderly patients (those $>65$ years of age) tended to have a greater number of bacterial co-infections that led to AECOPD, compared with non-elderly patients (48). Considering that lung inflammation status may vary among COPD patients from different regions, it is necessary to conduct multi-center studies in the future to evaluate the effects of the Yiqigubiao pill on AECOPD in elderly and non-elderly participants. Furthermore, it was observed that the majority of AECOPD cases in this trial were level I, resulting in the symptoms of AECOPD requiring only treatment at home (Table IV). The results of the present study also suggested that the Yiqigubiao pill would act as an adjunct to conventional therapy that is able to control relatively stable COPD.

The possible adverse reactions associated with the administration of the Yiqigubiao pill used in combination with other COPD therapies were the focus of the present study. The 11 cases of adverse reaction in the present study were determined to have no direct association with this 
trial according to the judgment of The Safety Monitoring Committee.

In conclusion, to the best of our knowledge, this is the first trial verifying that the Yiqigubiao pill is an efficient and safe drug in enhancing the treatment of stable COPD by reducing the occurrence of $\mathrm{AE}$ and improving the quality of life of patients.

\section{Acknowledgements}

The present study was financially supported by the Xinjiang Uighur Autonomous Region Science and Technology Planning Project of China (grant nos. 201233139 and 2012017).

\section{References}

1. Lin HH, Murray M, Cohen T, Colijn C and Ezzati M: Effects of smoking and solid-fuel use on COPD, lung cancer, and tuberculosis in China: A time-based, multiple risk factor, modelling study. Lancet 372: 1473-1483, 2008.

2. Chapman KR, Mannino DM, Soriano JB, Vermeire PA, Buist AS, Thun MJ, Connell C, Jemal A, Lee TA, Miravitlles M, et al: Epidemiology and costs of chronic obstructive pulmonary disease. Eur Respir J 27: 188-207, 2006.

3. Lopez AD, Shibuya K, Rao C, Mathers CD, Hansell AL, Held LS, Schmid V and Buist S: Chronic obstructive pulmonary disease: Current burden and future projections. Eur Respir J 27: 397-412, 2006.

4. Global Initiative for Chronic Obstructive Lung Disease: Global strategy for the diagnosis, management and prevention of chronic obstructive pulmonary disease (Revised 2011). Accessible at http://www.goldcopd.com.

5. Almansa R, Socias L, Andaluz-Ojeda D, Martín-Loeches I, BobilloF,Blanco J,Rico L, Berezo JÁ,Estella Á,Sanchez-GarciaM, et al: Viral infection is associated with an increased proinflammatory response in chronic obstructive pulmonary disease. Viral Immunol 25: 249-253, 2012.

6. Lugade AA, Bogner PN, Thatcher TH, Sime PJ, Phipps RP and Thanavala Y: Cigarette smoke exposure exacerbates lung inflammation and compromises immunity to bacterial infection. J Immunol 192: 5226-5235, 2014

7. Calverley PM and Walker P: Chronic obstructive pulmonary disease. Lancet 362: 1053-1061, 2003.

8. Daga MK, Khan NA, Malhotra V, Kumar S, Mawari G, Hira S: Study of body composition, lung function, and quality of life following use of anabolic steroids in patients with chronic obstructive pulmonary disease. Nutr Clin Pract 29: 238-245, 2014.

9. Falk JA, Minai OA and Mosenifar Z, Inhaled and systemic corticosteroids in chronic obstructive pulmonary disease. Proc Am Thorac Soc 5: 506-512, 2008.

10. Singh D: New combination bronchodilators for chronic obstructive pulmonary disease: Current evidence and future perspectives. Br J Clin Pharmacol 79: 695-708, 2015.

11. Greulich T, Koczulla AR, Nell C, Kehr K, Vogelmeier CF, Stojanovic D, Wittmann M and Schultz K: Effect of a three-week inpatient rehabilitation program on 544 consecutive patients with very severe COPD: A retrospective analysis. Respiration 90 287-292, 2015.

12. Gupta P and O'Mahony MS: Potential adverse effects of bronchodilators in the treatment of airways obstruction in older people: Recommendations for prescribing. Drugs Aging 25: 415-443, 2008.

13. Singh S, Loke YK and Furberg CD: Inhaled anticholinergics and risk of major adverse cardiovascular events in patients with chronic obstructive pulmonary disease: A systematic review and meta-analysis. JAMA 300: 1439-1450, 2008.

14. Lee TA, Pickard AS, Au DH, Bartle B and Weiss KB: Risk for death associated with medications for recently diagnosed chronic obstructive pulmonary disease. Ann Intern Med 149: 380-390, 2008.

15. Jian XY, Huang ZQ, Lai X, Chen WY and Jiang RB: A clinical study on the effects of Pingchuan capsule on BODE index in COPD patients at stable stage. Journal of Beijing University of Traditional Chinese Medicine 19: 32-34, 2012 (In Chinese).
16. Jiang FC, Yan Y, Yang L, Song Q and Li YL: Impact of chinese herb on quality of life of stable chronic obstructive pulmonary disease: A randomized controlled study. Zhongguo Zhong Yao Za Zhi 36: 3203-3206, 2011 (In Chinese).

17. Yu XQ, Li JS and Li L: A study on distributional regularity of TCM syndromes in chronic obstructive pulmonary disease patients. China Journal of Chinese Medicine 4: 44-46, 2003 (In Chinese).

18. Yu QH and Qiu ZN: Analysis of diagnosis and treatment of chronic obstructive pulmonary disease. Chinese Archives of Traditional Chinese Medicine 21: 1190, 2003 (In Chinese).

19. Li HW and Li HJ: A report on 150 cases of recurrent airway inflammation treated with Yiqigubiao formula in teenagers. Lishizhen Medicine and Materia Medica Research 17: 626-627, 2006 (In Chinese).

20. Li M, Qu CY and Zhui AQ: A clinical study on 80 cases of allergic rhintis treated with Yiqigubiao therapy. China Modern Doctor 46: 104-111, 2008 (In Chinese).

21. Yang Q, Xu Y, Feng G, Hu C, Zhang Y, Cheng S, Wang Y and Gong X: p38 MAPK signal pathway involved in anti-inflammatory effect of Chaihu-Shugan-San and Shen-ling-bai-zhu-San on hepatocyte in non-alcoholic steatohepatitis rats. Afr J Tradit Complement Altern Med 11: 213-221, 2014.

22. Zhu Y and Liu X: Treatment of chronic bronchitis with modified ma xing shi gan tang and er chen tang. J Tradit Chin Med 24: 12-13, 2004.

23. Zheng YS, Wu ZS, Ni HB, Ke L, Tong ZH, Li WQ, Li N and Li JS: Codonopsis pilosula polysaccharide attenuates cecal ligation and puncture sepsis via circuiting regulatory $\mathrm{T}$ cells in mice. Shock 41: 250-255, 2014

24. Fu L and $\mathrm{Yu} \mathrm{M}$ : New progression on study of Poria cocos. Xinjiang Journal of Traditional Chinese Medicine 23: 79-82, 2005 (In Chinese).

25. Hong MH, Kim JH, Bae H, Lee NY, Shin YC, Kim SH and Ko SG: Atractylodes japonica Koidzumi inhibits the production of proinflammatory cytokines through inhibition of the NF-kappaB/IkappaB signal pathway in HMC-1 human mast cells. Arch Pharm Res 33: 843-851, 2010.

26. Celli BR and MacNee W; ATS/ERS Task Force: Standards for the diagnosis and treatment of patients with COPD: A summary of the ATS/ERS position paper. Eur Respir J 23: 932-946, 2004.

27. Morales-Blanhir JE, Palafox Vidal CD, Rosas Romero Mde J, Garcia Castro MM, Londoño Villegas A and Zamboni M: Six-minute walk test: A valuable tool for assessing pulmonary impairment. J Bras Pneumol 37: 110-117, 2011. (In Portuguese).

28. Mahler DA and Wells CK: Evaluation of clinical methods for rating dyspnea. Chest 93: 580-586, 1988.

29. Jones PW, Harding G, Berry P, Wiklund I, Chen WH and Kline Leidy N: Development and first validation of the COPD Assessment Test. Eur Respir J 34: 648-654, 2009.

30. Celli BR, Cote CG, Marin JM, Casanova C, Montes de Oca M, Mendez RA, Pinto Plata V and Cabral HJ: The body-mass index, airflow obstruction, dyspnea and exercise capacity index in chronic obstructive pulmonary disease. N Engl J Med 350: 1005-1012, 2004.

31. Richardson K. and Weinberg A: Dynamics of regulatory T-cells during pregnancy: Effect of HIV infection and correlations with other immune parameters. PLoS One 6: e28172, 2011.

32. Li JS and Wang MH: Clinical significance of acute exacerbation in chronic obstructive pulmonary disease. Zhongguo Wei Zhong Bing Ji Jiu Yi Xue 19: 572-573, 2007 (In Chinese).

33. The Lung Health Study Research Group: Effect of inhaled triamcinolone on the decline in pulmonary function in chronic obstructive pulmonary disease. N Engl J Med 343: 1902-1909, 2000.

34. Tashkin DP, Celli B, Senn S, Burkhart D, Kesten S, Menjoge S and Decramer M; UPLIFT Study Investigators: A 4-year trial of tiotropium in chronic obstructive pulmonary disease. N Engl J Med 359: 1543-1554, 2008.

35. Wang JJ, Rochtchina E, Tan AG, Cumming RG, Leeder SR and Mitchell P: Use of inhaled and oral corticosteroids and the long-term risk of cataract. Ophthalmology 116: 652-657, 2009.

36. Hougardy DM, Peterson GM, Bleasel MD and Randall CT: Is enough attention being given to the adverse effects of corticosteroid therapy? J Clin Pharm Ther 25: 227-234, 2000.

37. Li J, Zhang F and Li J. The immunoregulatory effects of traditional Chinese medicine on treatment of asthma or asthmatic Inflammation. Am J Chin Med 43: 1059-1081, 2015. 
38. Wang HF, Zhang HL, Li JS, Yu YQ, Lu SY,Li B, Xie Y and Bai YP: Effectiveness and safety of traditional Chinese medicine on stable chronic obstructive pulmonary disease: A systematic review and meta-analysis. Complement Ther Med 23: 603-611, 2015.

39. The Committee of Pulmonary Disease: China Association of Traditional Chinese Medicine: The diagnostic standard on symptoms of COPD in Chinese medicine (version 2011). Journal of Traditional Chinese Medicine 2: 177-178, 2012 (In Chinese).

40. Hu J and Meek P: Health-related quality of life in individuals with chronic obstructive pulmonary disease. Heart Lung 34: 415-422, 2005.

41. O'Donnell DE, Lam M and Webb KA: Measurement of symptoms, lung hyperinflation, and endurance during exercise in chronic obstructive pulmonary disease. Am J Respir Crit Care Med 158: 1557-1565, 1998.

42. Hogg JC, Chu F, Utokaparch S, Woods R, Elliott WM, Buzatu L, Cherniack RM, Rogers RM, Sciurba FC, Coxson HO and Par PD: The nature of small-airway obstruction in chronic obstructive pulmonary disease. N Engl J Med 350: 2645-2653, 2004.
43. Babusyte A, Jeroch J, Stakauskas R, Stravinskaite K, Malakauskas K and Sakalauskas R: The effect of induced sputum and bronchoalveolar lavage fluid from patients with chronic obstructive pulmonary disease on neutrophil migration in vitro. Medicina (Kaunas) 46: 315-322, 2010.

44. Lin WS: Clinical study of allergic rhinitis treated by 'bu qi gu biao'. Zhong Xi Yi Jie He Za Zhi 9: 263-265, 1989 (In Chinese).

45. Rios JL: Chemical constituents and pharmacological properties of Poria cocos. Planta Med 77: 681-691, 2011.

46. Li CQ, He LC, Dong HY and Jin JQ: Screening for the anti-inflammatory activity of fractions and compounds from Atractylodes macrocephala koidz. J Ethnopharmacol 114: 212-217, 2007.

47. Hyam SR, Jang SE, Jeong JJ, JohEH,Han MJ and Kim DH: Echinocystic acid, a metabolite of lancemaside A, inhibits TNBS-induced colitis in mice. Int Immunopharmacol 15: 433-441, 2013.

48. Dimopoulos G, Tsiodras S, Lerikou M, Chranioti A, Perros E, Anagnostopoulou U, Karakitsos P and Armaganidis A: Viral profile of COPD exacerbations according to patients. Open Respir Med J 9: 1-8, 2015. 